\title{
ABORDAGENS E CONTRIBUIÇÕES HISTÓRICAS DA GRÃ-BRETANHA PARA A CIÊNCIA DA INFORMAÇÃO: UM OLHAR A PARTIR DO CLASSIFICATION RESEARCH GROUP
}

\author{
APPROACHES AND HISTORICAL CONTRIBUTIONS OF \\ GREAT BRITAIN TO INFORMATION SCIENCE: A LOOK \\ FROM THE CLASSIFICATION RESEARCH GROUP
}

\author{
Sarah Migliolia \\ Déborah Araujo
}

\begin{abstract}
RESUMO
Introdução: As perspectivas utópicas refletidas na Literatura durante o fim do século XIX e início do século XX são ambiente fértil para o surgimento da relevância história da Grã-Bretanha para a área da Classificação. Traça um panorama histórico da Ciência da Informação na Grã-Bretanha, descrevendo a relevância e o pioneirismo do Classification Research Group e seus membros. Objetivos: Tem como objetivo abordar o despertar científico sob a influência de utopias literárias, que culminaram no desenvolvimento de métodos de classificação para organização do conhecimento, através das abordagens e contribuições da Grã-Bretanha à luz da trajetória do Classification Research Group. Metodologia: A metodologia da pesquisa descritiva inclui levantamento documental e revisão de literatura acerca da temática, sob a influência da espinha dorsal da obra comemorativa editada por Gilchrist (2009). Resultados: Identificou-se a influência histórica do período das utopias na perspectiva de trabalho na Ciência da Informação dos pesquisadores do Classification Research Group. Conclusão: Conclui com o reconhecimento do papel da Grã-Bretanha e do pioneirismo do Classification Research Group, essencialmente pelo trabalho precursor da análise de facetas para a recuperação de informação, estabelecido como fundamental para a construção de todo um espectro de ferramentas de busca de informação até hoje, e pela a fundação do primeiro curso de pós-graduação em Ciência da Informação.
\end{abstract}

Descritores: Ciência da Informação. Organização do Conhecimento. História da Classificação. Classification Research Group. Utopia.

\footnotetext{
a Doutora em Ciência da Informação no Instituto Brasileiro de Informação em Ciência e Tecnologia (IBICT) e Universidade Federal do Rio de Janeiro (UFRJ). Bibliotecária do Instituto Nacional de Educação de Surdos (INES/MEC). E-mail: smiglioli@gmail.com.

b Mestre em Ciência da Informação no Instituto Brasileiro de Informação em Ciência e Tecnologia (IBICT) e Universidade Federal do Rio de Janeiro (UFRJ). E-mail: daraujocontato@gmail.com.
} 


\section{INTRODUÇÃO}

Os registros acerca do surgimento da Ciência da Informação apresentam evidências históricas que denotam a importância e influência da Grã-Bretanha no estabelecimento do campo. O papel exercido pelos seus pesquisadores foi de grande impacto nas descobertas da área da Ciência da Informação e ainda hoje reverberam sua influência. Devido à herança basilar e por haver pouco estudo dedicado à temática esse tema se mostra relevante para a área da Ciência da Informação.

O avanço da ciência, como também sua difusão em muitos aspectos da vida econômica, social e intelectual ocorrido após a segunda revolução industrial no final do século XIX e início do século $X X$, fez com que os estados e sociedades industriais modernas passassem pelo processo de cientifização. $O$ ritmo acelerado desses avanços científicos e técnicos que foram acumulados particularmente no início do século $X X$ incentivou o início de uma revolução científica. A manifestação mais visível dessa revolução foi o fenômeno da "explosão da informação", que se refere ao crescimento exponencial de registros de informações e publicações científicas e técnicas.

Neste sentido, emerge a Documentação, entendida pelos membros que a propuseram como um fator histórico no desenvolvimento da organização global na modernidade. Tal visão advém a partir da crença de que a organização do conhecimento seria um pré-requisito para as relações internacionais pacíficas, como exemplificou Paul Otlet, o pai da Documentação e idealizador do Mundaneum (PINHEIRO, 2002).

No início do século $X X$, a classificação e uso da informação foram considerados essenciais para o crescimento industrial e a consolidação do poder do Estado. A motivação para a classificação e Documentação permeou todo o espectro político e poderia servir a diferentes agendas políticas.

A partir desse contexto, torna-se importante traçar o panorama histórico em que estavam inseridos os cientistas da informação britânicos que influenciaram o campo, e determinar o contexto do seu surgimento, tanto histórico como ideológico. Para tanto, aborda-se o desenvolvimento científico na 
Grã-Bretanha e a força que utopias como a de Herbert George Wells exerceram na época de atuação que veio a propiciar a criação do Classification Research Group.

Em levantamento realizado sobre o tema, merece destaque no âmbito internacional, a coletânea intitulada "Information Science in transition", editada por Alan Gilchrist e publicada em 2009. A obra foi editada em comemoração aos 50 anos do Institute for Information Scientists, completados em 2008, mencionada também por Pinheiro (2013b). Tal destaque se justifica pelo fato de a publicação trazer referências à congregação de autores pioneiros da Ciência da Informação na Grã-Bretanha. A obra apresenta trabalhos de autoria de David Bawden, Stella Dextre Clark, Tom Wilson, Blaise Cronin, Peter Willet, Elisabeth Davenport, Charles Oppenheim, Peter Enser, Wendy Warr, Mike Thelwall, Barry Mahon, Stephen Robertson, Peter Banheira e Eugene Garfield, além de editorial de Brian Vickery. Os capítulos abordam autores e ideias preliminares, e segue até os temas atuais desenvolvidos na área da Ciência da Informação na GrãBretanha.

Sobre o tema, no Brasil, Pinheiro (2013) trata especificamente dessa abordagem,assim como Barreto (2007), e por outros autores mais brevemente, como em Freire (2006). Isso porque os países que compõem a Grã-Bretanha tiveram papel relevante junto aos marcos históricos no desenvolvimento da ciência e tecnologia (C\&T) e, portanto, torna-se importante abordar as influências desses pioneiros no panorama da área.

Outras obras que abordam o tema em específico (JUSTICE, 2004; MUDDIMAN, 2008; BLACK;MUDDIMAN;PLANT, 2007; BROUGHTON, 2011) foram relevantes para a elaboração da pesquisa. Devido à originalidade da temática e a relevância para a área, optou-se por enfatizar o contexto científico do panorama histórico e o papel do expoente Classification Research Group para o campo da Ciência da Informação.

O objetivo deste estudo é descrever a relevância e o pioneirismo do Classification Research Group e seus membros para a Ciência da Informação, traçado sob a perspectiva da influência das utopias, destacando seu papel para a conjuntura da Ciência da Informação na Grã-Bretanha à época. A partir de 
levantamento do panorama histórico da área, objetiva traçar os agentes (autores, eventos, publicações) exponenciais enfocando o Classification Research Group, e contextualizar o impacto da Grã-Bretanha sobre os métodos de classificação da Organização do Conhecimento.

Este artigo se caracteriza como uma pesquisa descritiva, e para atingir o objetivo proposto foi realizado levantamento documental e biobibliográfico, por meio de revisão de literatura acerca da temática. Os critérios para a composição do corpus utilizado para a revisão de literatura em termos de sua representatividade destacaram trabalhos sobre o enfoque específico tratado, em especial a espinha dorsal apresentada na obra sistemática comemorativa organizada por Gilchrist (2009) que traz conteúdos fundamentais acerca dos, então, 50 anos de pesquisa em Ciência da informação pela Grã-Bretanha. Os procedimentos metodológicos usados tiveram como base a abordagem histórica, a partir do recorte dos agentes de origem específica, no caso, da região geográfica da Grã-Bretanha, que engloba os países Inglaterra, Escócia e País de Gales.

O desenvolvimento da ciência na Grã-Bretanha, a influência das utopias sobre a Ciência da Informação britânica, e o pioneirismo do Classification Research Group serão abordados neste artigo.

\section{DESENVOLVIMENTO DA CIÊNCIA NA GRÃ-BRETANHA}

Com o início do século XVI, origina-se o apontar da ciência moderna que nos séculos posteriores desenvolve seu estabelecimento ao ser influenciada por correntes de pensamento difundidas naquele período da história. O processo é impulsionado pela institucionalização da ciência, por meio do surgimento de sociedades e periódicos científicos pioneiros.

É a partir do nascimento da ciência moderna no século 16, e de sua institucionalização e consolidação nos séculos 17 e 18, com o iluminismo e o domínio da razão, que se instauram as primeiras sociedades científicas e circulam os periódicos científicos pioneiros, instrumentos legitimadores da ciência, na medida da avaliação e validação de resultados de pesquisas pelos pares (PINHEIRO, 2002, p. 5). 
A sociedade científica que primeiro se estabeleceu foi a Royal Society of London (1660), instituição britânica que partilhava entre seus membros os descobrimentos das investigações científicas e pesquisas, promovendo já desde seus primórdios o compartilhamento e a validação entre pares, apontando papéis importantes como o de autoria, pares na ciência, comunicação científica, entre outros.

A formalização do processo de comunicação científica foi realizada com o surgimento do periódico científico Journal dês Sçavans (1665), que posteriormente foi descontinuado, seguido do Philosophical Transactions of the Royal Society (1665), da Royal Society of London (MEADOWS, 1974; GARVEY, 1979; ZIMAN, 1979).

Segundo Muddiman (2008, p. 201), já na segunda metade do século XIX, a ciência britânica principia a deixar o amadorismo da Era Vitoriana e abre caminho para instituições, redes e organizações sociais da ciência moderna. Os principais elementos da ciência pública moderna que se tornaram visíveis na Grã-Bretanha nesse período segundo o autor foram: o surgimento de um lobby de ciência, contando com instituições e indivíduos com grande perfil público e midiático; a fundação de um estado de ciência que assumiria um papel de liderança na subvenção e modelação da pesquisa e desenvolvimento; a adoção do método científico para as atividades de administração, governança e produção industrial; e a expansão da educação científica, resultando no surgimento de uma classe profissional de cientistas.

A partir dessa nova perspectiva de ênfase nas questões relativas à informação, levantou-se a questão sobre a inadequação das abordagens tradicionais no tratamento, organização, recuperação e disseminação da informação, baseados fortemente em bibliotecas e no livro impresso (MUDDIMAN, 2008). Como resultado, técnicas sistemáticas de processamento de informação começaram a ser desenvolvidas, em paralelo com a emergência da disciplina Documentação e pouco mais tarde com a Ciência da Informação.

A primeira geração de documentalistas tinha o compromisso de servir aos usuários clássicos do período que antecedeu a Primeira Guerra Mundial, como as universidades de elite, professores pesquisadores de longa data que 
trabalhavam de forma independente, e pesquisadores que estabeleceram organizações científicas. Após a eclosão da Primeira Guerra Mundial, uma nova geração apareceu, e estes passaram então a atuar na área chamada Ciência da Informação.

No mundo da emergência profissional da Documentação e Biblioteconomia especializada, o apoio às atividades de informação oferecidas pelo governo britânico foi refletido no número de cientistas que se tornaram documentalistas - um fenômeno que posteriormente incorporou a criação do título de "cientista da informação". Suas diferentes formações profissionais foram cruciais para a criação de uma Ciência da Informação ligada às novas variedades do campo de atuação da área, na construção de novos sistemas e na criação do núcleo metodológico do auge da Ciência da Informação (BURKE, 2007).

A convergência de alguns fatores contribuiu para o surgimento da Ciência da Informação, a saber:

O avanço científico e tecnológico, principalmente em função da Segunda Guerra Mundial e, consequentemente, a "explosão bibliográfica"; a necessidade social, histórica, cultural e política do registro e transmissão dos conhecimentos e informações, produto do processo de desenvolvimento da Ciência e Tecnologia; e o surgimento de novas tecnologias a partir do microfilme e, principalmente, do computador" (PINHEIRO, 2002, p. 8).

A principal missão dos cientistas da informação era investigar e melhorar os chamados serviços bibliográficos "secundários", adicionando a esse trabalho a indexação, eficiente recuperação, tradução automática e indexação automática, além de novas ferramentas para a identificação de fotografias e seus conteúdos (BURKE, 2007). Grande parte do trabalho ocorreu dentro das agências governamentais amplamente expandidas. Cientistas da informação procuravam estruturas integradas de classificação que poderiam gerir os novos documentos. Disseminavam-se expectativas de que as novas pesquisas de informação levassem à descoberta de leis fundamentais de informação, além das estatísticas anteriores no uso da palavra e taxas de publicação criadas nos anos pré-guerra por inovadores como Zipf e Bradford (BURKE, 2007). 
Neste contexto, o impulso para o desenvolvimento da Ciência da Informação foi assistido na Grã-Bretanha pelo avivamento, a partir da década de 1870 em diante, da utopia científica. Utopias literárias apoiadas por pesquisa científica tiveram uma longa linhagem na Grã-Bretanha, mas o alvorecer do século XX favoreceu a fusão dessas utopias com o racionalismo científico moderno e a sua adoção como uma justificativa para novas técnicas de processamento de informação (RAYWARD, 2008).

A etimologia do termo "utopia" se origina dos radicais grego "ou", advérbio de negação "não", somado a "tópos", no sentido de lugar, ou seja, utopia seria o "não-lugar" ou "lugar que não existe" (JAPIASSÚ; MARCONDES, 2001, p. 192). O conceito de utopia foi criado por Thomas More (1477-1535) - também conhecido como Thomas Morus - humanista inglês, em 1516. More (2015) intitulou sua obra "Utopia", na qual descreve uma ilha imaginária, um local idílico, novo e inocente, onde haveria igualdade na divisão de bens sociais e o comprometimento com a coletividade. A ilha "Utopia" e o povo "utopiano" foram inspirados nas narrativas de Américo Vespúcio sobre a recém-avistada ilha em 1503, como afirma no capítulo "Livro Primeiro" da obra (MORE, 2015, p. 59).

Esse despertar da utopia científica sofreu, à época, impactante influência de utopias literárias. A campanha de Herbert George Wells - mais conhecido como H. G. Wells - para uma "Organização Mundial Enciclopédica", do início dos anos 1920 em diante, sintetizou este processo. Com suas origens nas obras de Wells da virada do século, como a obra "A Utopia Moderna" (1905), e sua apoteose documentada na publicação "World Brain", do final dos anos 1930 (RAYWARD, 2008, p. 225), uma visão do acesso universal à informação que era internacionalizada, tecnologicamente inovadora e burocrática teve fértil oportunidade para progredir.

\section{INFLUÊNCIA DAS UTOPIAS SOBRE A CIÊNCIA DA INFORMAÇÃO BRITÂNICA}

Herbert G. Wells e Thomas Henry Huxley foram expoentes da perspectiva das utopias evidenciadas na literatura, tendo seu início na Grã-Bretanha. Podese perceber pela trajetória biográfica de Wells (1866-1946) o caminho seguido 
para chegar até o seu reconhecimento - Wells foi aluno de Biologia, sendo também estudioso da ciência, na Escola Normal de Ciências em Londres, junto com Thomas Henry Huxley, que exerceu forte influência sobre sua obra (CLUTE, STABLEFORD, 2016).

Huxley foi um dos principais defensores públicos da teoria da evolução de Charles Darwin, além de um dos grandes cientistas ingleses do século XIX. Segundo Leonard Huxley (1901), seu descendente, Thomas Henry Huxley teve grande destaque na área da ciência, recebendo prêmios e assinando descobertas científicas no âmbito da medicina. Por conta do seu destaque e fama, obteve acesso aos pesquisadores de destaque à época da ciência inglesa, incluindo Charles Darwin. Foi renomado não apenas pelos seus méritos acadêmicos na ciência, mas por sua forte influência para além do âmbito científico. Thomas Huxley veio a ser o avô de Aldous Huxley, autor da reconhecida obra de ficção científica "Admirável Mundo Novo" (1932), que aborda um contexto de um futuro onde as pessoas são pré-condicionadas biologicamente, tratando também de temas extremamente atuais como clonagem e ética na ciência.

Influenciado não só por T. H. Huxley, mas por outros autores como Platão, o biólogo e cientista Herbert $\mathrm{G}$. Wells publicou diversos romances literários. Suas obras são descritas como "romances científicos", pois tratavam de utopias sobre o fim do mundo e sobre a forma como o futuro seria interferido pela ciência e pela tecnologia. Ficou conhecido por ser o pai da ficção científica, por obras como "A máquina do tempo", "O homem invisível", "A guerra dos mundos", "Os dias do cometa", bem como o famoso "World Brain", que veio a influenciar cientistas da informação da época (WELLS, 1967, p. 612).

Em sua autobiografia intitulada "Experiment in autobiography: discoveries and conclusions of a very ordinary brain (since 1866)", publicada em 1934, Wells se descreve como um trabalhador mental, cujos pensamentos e trabalho estão sobrecarregados com reivindicações (WELLS, 1967, p. 112). O autor relata em sua autobiografia diversos traços da sua vida pessoal, descreve ainda sua crença na inevitabilidade de um Estado mundial e na insuficiência completa dos 
métodos parlamentares de governo democrático, narrando sua devoção para com uma grande civilização do futuro.

O ímpeto para o desenvolvimento dessa nova ciência foi sem dúvida assistido na Grã-Bretanha pelo resgate, a partir de 1870, das utopias científicas, e mais especialmente pela inclusão do novo conceito de informação no contexto utópico. A campanha de Wells por uma Organização Enciclopédica Mundial dentro de sua obra atendia a esse ideal. A obra "World Brain", ficção científica pioneira inglesa, descreve a visão de um cérebro mundial que poderia ajudar os cidadãos do mundo a fazer o melhor uso dos recursos de informação universais e a contribuir para a paz mundial (como o Mundaneum de Paul Otlet em 1910 e o artigo "As we may think" de Vannevar Bush em 1945). Mais especificamente na Inglaterra, H. G. Wells, bem como Otlet, ofereceram o contexto para um pequeno grupo de cientistas e documentalistas que, entusiasticamente, começaram a aplicar os principais elementos dessa utopia ao cenário da informação na Grã-Bretanha (BLACK; MUDDIMAN; PLANT, 2007).

A proposta de H. G. Wells de um cérebro mundial combinava o enciclopedismo com uma visão mais ampla das relações globais. À luz de tais concepções de Classificação e Documentação, pode-se entender por que a informação teve grande importância no trabalho de organizações como a Liga das Nações. As diferentes agências do sistema da Liga ficaram ocupadas coletando e classificando diversos tipos de informações, de estatísticas econômicas até dados sobre a saúde pública (BLACK; MUDDIMAN; PLANT, 2007).

Na Grã-Bretanha, a tentativa de Wells de estabelecer uma enciclopédia mundial teve influência duradoura. A disseminação de seus ideais proporcionou a difusão do conhecimento que Wells esperava, ou seja, promover a paz mundial e o desenvolvimento educacional. Segundo Black, Muddiman e Plant (2007), as propostas tinham caráter internacional, contendo a campanha para uma organização mundial de enciclopédia que empregaria milhões de pessoas em todo o mundo. O conhecimento armazenado e recuperado usando tecnologia inovadora de microfilme seria reunido e disseminado em todo o mundo através de uma rede postal vasta, incluindo subcentros nacionais e uma série de 
publicações periodicamente revisadas. Embora Wells tenha morrido em 1946, antes que qualquer um desses planos pudesse ser realizado, suas ideias influenciaram pensadores como Bernal, na Grã-Bretanha e Vannevar Bush nos Estados Unidos, este último comumente considerado como tendo enunciado o arquétipo moderno de progresso através do acesso à informação.

O sonho de H. G. Wells de um cérebro mundial e a pré-Primeira Guerra Mundial academicamente ligaram esforços no desenvolvimento de métodos de classificação gerais para se organizar tão abrangente conhecimento e que culminaram no trabalho pioneiro do Classification Research Group (CRG).

\section{OPIONEIRISMO DO CLASSIFICATION RESEARCH GROUP}

No final da década de 1940, tiveram início os primeiros acontecimentos que vieram a dinamizar o surgimento da Ciência da Informação. A natureza interdisciplinar da Ciência da Informação é elemento característico e constituidor do campo. A complexidade do conceito que aborda em seu objeto de estudo - a informação - tem muito a contribuir para o enredamento desta área de estudo. Nesse sentido, a contribuição britânica mais significativa para o campo da Ciência da Informação talvez seja a proporcionada pelas teorias da classificação.

Em 1948, a Royal Society realizou uma conferência sobre informação científica em Londres, a Royal Society Scientific Information Conference. Uma das consequências da conferência foi que a Royal Society (Londres, 1660-) expressou um interesse na classificação da literatura científica e, além disso, deliberou a criação de um grupo de estudo formado por cientistas para atuar com foco nessa área (BROUGHTON, 2011).

Segundo Broughton (2011), Brian Vickery foi convidado a convocar um grupo de pesquisadores interessados e, em 1952, o Classification Research Group (CRG) foi formado. O ambiente era de profunda preocupação com a gestão da explosão da informação científica. Entre os participantes estavam Vickery, bibliotecário da Imperial Chemical Industries, Derek Austin, Eric Coates, Jason Farradane, Robert Fairthorne, Douglas Foskett, Barbara Kyle, Derek Langridge, Jack Mills, e Bernard Palmer (BROUGHTON, 2011, p. 322). 
O expoente influenciador e padrinho intelectual de muitas das discussões e trabalhos do CRG, mesmo sem estar presente, foi o matemático e bibliotecário indiano Shiyali Ramamrita Ranganathan, criador da técnica da análise facetada na classificação. O membro do grupo Douglas Foskett, já familiarizado com o trabalho de Ranganathan, desenvolveu uma classificação facetada para sua área de atuação, a metalurgia, e posteriormente publicou os resultados de seus estudos no livro Classification in the Social Sciences (FOSKETT, 1963).

Durante a década de 1950, o CRG se concentrou particularmente na estrutura das classificações especializadas e propôs novas teorias para armazenar e recuperar a informação, com enfoque no grande volume de informação. Todos os seus membros se envolveram ativamente na temática das classificações, e seu modo básico de trabalho era tomar problemas concretos específicos do trabalho, discuti-los e generalizá-los, de forma a construir um corpus de conceitos e princípios que poderiam guiar trabalhos futuros (BROUGHTON, 2011).

Dos membros que fizeram parte do $C R G$, será apresentado o enfoque em relação à atuação de Jason Farradane, John Desmond Bernal, Brian Vickery, Jack Mills, Robert Fairthorne e Douglas Foskett, devido ao impacto que o pioneirismo de suas pesquisas causou na Ciência da Informação.

Entre os membros do Classification Research Group destaca-se o britânico Jason Farradane (1906-1989), pelo importante legado que deixou para a Ciência da Informação. Com formação em Química pelo Imperial College (1929), começou a trabalhar na indústria como químico e documentalista. Depois de se envolver com pesquisa no Ministério de Abastecimento e no Almirantado da Grã-Bretanha durante a Segunda Guerra Mundial, Farradane causou seu primeiro impacto com um trabalho sobre a abordagem científica para a documentação em uma Conferência de Informação Científica da Royal Society em 1948 (BROUGHTON, 2011).

Nascido como Jason Lewkowitsch, seu compromisso com a ciência se refletiu no sobrenome que ele criou para si mesmo - uma combinação do sobrenome de Michael Faraday (1791-1867) - da área de eletromagnetismo e eletroquímica - e John Burdon Sanderson Haldane (1892-1964) - da área de 
psicologia e biologia genética e evolucionária, dois cientistas que ele particularmente admirava (BROUGHTON, 2011). Para a pesquisa, suas principais contribuições foram sobre a análise relacional, em um trabalho precursor para a área de inteligência artificial e no conceito de informação.

Jason Farradane e John Desmond Bernal encabeçaram a criação do Institute for Information Scientists (IIS) em 1958. O estabelecimento do termo "Information Science" data de 1960, registrado pelo Oxford English Dictionary (OED) em referência a um artigo de Saul Gorn de 1958, da área de computação, que inaugura o termo com a criação do IIS. Jason Farradane, entretanto, usou "Information Scientist" antes do registro pelo OED, em um artigo publicado em 1953 (ALVARES; ARAÚJO JÚNIOR, 2010, p. 197).

$\mathrm{Na}$ Inglaterra, e no resto do mundo, estes acontecimentos, desde a publicação do "As we may think" até a Conferência de 1948 da Royal Society, provocaram uma cisão com a Biblioteconomia que durou perto de 40 anos. Um ano após a Conferência da Royal Society de Londres, Jason Farradane, J. Bernal e outros criaram o Institute for Information Scientists, para acolher as novas ideias e os novos pesquisadores surgidos nesta "nova" área (BARRETO, 2007, p. 22).

Conforme Barreto (2007), Farradane teve importante atuação no contexto da Grã-Bretanha e sua influência na Ciência da Informação. Farradane também foi o fundador do primeiro curso de pós-graduação em Ciência da Informação, em 1963, na City University of London, Inglaterra. Nesta mesma instituição se tornou diretor do Centro de Ciência da Informação, em 1966.

Nos anos 1970, Farradane enumerou as competências específicas dos novos profissionais da Ciência da Informação, como: comunicação humana, técnicas de investigação, fontes de informação, catalogação, indexação e classificação, apresentação da informação, administração, reprodução documentária e leis de direito autoral (FARRADANE, 1950, 1979). Farradane preocupou-se ainda em desenvolver a indexação relacional, que tinha como objetivo preservar a semântica implícita pretendida pelo indexador quanto aos pares de conceitos no momento da recuperação (ALVARES; ARAÚJO JÚNIOR, 2010).

$\mathrm{Na}$ indexação relacional, Farradane, em 1980, define relações para associar esses pares de conceitos. Baseadas na psicologia do pensamento, as 
nove relações refletem a combinação dos mecanismos mentais de associação e discriminação no tempo e espaço que, segundo o autor, podem expressar as relações de aplicação geral em qualquer área de assunto e em qualquer nível de complexidade (ALVARES; ARAÚJO JÚNIOR, 2010).

Outro membro do grupo, John Desmond Bernal (1901-1971), irlandês', teve sua formação em Matemática e Ciência pela Universidade de Cambridge. Destacou-se como um dos pioneiros no estudo da cristalografia de raios e, em seu grupo de pesquisas de Cambridge, estava a britânica Dorothy Crowfoot Hodgkin (1910-1994), que recebeu o Prêmio Nobel de Química pelas pesquisas na área em 1964. Por sua vez, Bernal foi condecorado por suas pesquisas com a Medalha Real (1945), o Prêmio Guthrie Lecture (1947), o Prêmio Lenin da Paz (1953) e o Prêmio Bakerian Lecture (1962) (HODGKIN, 1980).

Bernal atuou principalmente no desenvolvimento de ideias relativas à introdução de novas políticas de informação no período de guerra. Uma de suas grandes contribuições foi a participação como uma das principais referências para o estabelecimento do Instituto de Informação Científica no Reino Unido e da introdução da Ciência da Informação como uma nova disciplina em 1948 (HODGKIN, 1980). No âmbito político, Bernal pode ser considerado uma importante liderança no que diz respeito ao desenvolvimento de ideias relativas à introdução de novas políticas de informação no período de guerra na GrãBretanha (BERNAL, 1939). Segundo Pinheiro (2013, p. 10), "o pensamento de ciência planejada, dedicada à paz, ao bem-estar e aos benefícios para humanidade, contido no seu livro, praticamente revolucionou o pensamento da época".

Brian Vickery (1918-2009), outro renomado membro do CRG, além de cientista da informação, era mestre em Química pela Universidade de Oxford (1941). Foi um importante expoente da Ciência da Informação na Grã-Bretanha, tendo emigrado ainda pequeno da Austrália para a Inglaterra. Atuou principalmente com os temas da classificação facetada, organização da

\footnotetext{
1 John Desmond Bernal (1901-1971) é proveniente da Irlanda, país que não faz parte do recorte geográfico deste artigo mencionado anteriormente, mas foi incluído pelo seu papel de relevante atuação dentro do Classification Research Group.
} 
informação e do conhecimento (VICKERY, 1978, 1980, 2004, 2008). Participou também de outras instituições como: Industrial Chemist Review, Akers Research Laboratories of the Imperial Chemical Industries, UK National Lending Library for Science and Technology e Escola de Biblioteconomia, Arquivo e Estudos de Informação, University College London. Assim como Farradane e outros membros, Vickery também advinha da área da Química, cujos pesquisadores muito contribuíram para os estudos de classificação naquele período (CRONIN, 2010).

Outro importante membro do CRG foi o britânico Jack Mills (1918-2010). Bibliotecário de formação atuou nas áreas da catalogação e classificação bibliográfica, além de ter trabalhado no desenvolvimento de uma edição revisada (BC2) da Bliss Bibliographic Classification. Teve grande impacto em aspectos como a organização do conhecimento e a recuperação da informação (MILLS, 1960). A influência de seu trabalho com o BC2 pode ser percebida em revisões de outros sistemas de classificação, thesaurus e vocabulários estruturados (BROUGHTON, 2010).

No Brasil, lecionou no programa de pós-graduação do Instituto Brasileiro de Informação em Ciência e Tecnologia (IBICT), instituição pioneira no país que em 1970 teve a colaboração e participação de professores estrangeiros devido à inexistência à época de professores doutores na área da Ciência da Informação no Brasil (PINHEIRO, 2007).

Outro membro, o inglês Robert Arthur Fairthorne (1904-2000) era formado em matemática pela University of London. Suas principais áreas de pesquisa envolviam a Bibliometria, como o envolvimento com a Lei de Bradford e a Lei de Zipf. Contribuiu para racionalizar e explicar as derivações e limitações do campo emergente da Bibliometria, além de ter estudado as limitações da teoria de Shannon e Weaver (FAIRTHORNE, 1947, 1961, 1967). Em 1967, recebeu o Prêmio de Mérito ASIS por seus esforços dedicados e pioneirismo na Ciência da Informação (WALKER, 1974).

Participante do CRG, Douglas John Foskett (1918-2004) foi outro bibliotecário inglês que atuou nas temáticas da classificação facetada, catalogação e disseminação seletiva da informação. Trabalhou em outras 
instituições como Bibliotecas Públicas em Ilford, Metal Box Company Limited, Biblioteca do Instituto de Educação de Londres e Biblioteca Serviços Centrais da University of London, além de ter sido presidente da Associação de Bibliotecas do Reino Unido (RAYWARD, 2000). Foskett foi expoente autor na área, publicando amplamente em serviços de informação (FOSKETT, 1963,1970).

Os membros originais do $C R G$ foram reunidos a partir de um círculo de cientistas cujas carreiras individuais já carregam mérito suficiente para provocar interesse em historiadores da ciência. Em 1955, foi publicado o Manifesto do CRG pela Library Association Record. A partir deste manifesto, os membros se comprometeram em tornar a classificação facetada a base de toda a recuperação da informação e estabeleceram os princípios gerais da teoria e metodologia para atingir esse fim (BROUGHTON, 2006, 2011).

A pesquisa e $\mathrm{o}$ trabalho teórico do grupo envolveram principalmente $\mathrm{O}$ estudo da análise facetada, desenvolvida por Ranganathan na década de 1930 (BROUGHTON, 2011). A teoria defende o agrupamento de termos de um dado campo do conhecimento em facetas homogêneas e mutuamente exclusivas, derivadas de suas facetas superiores por uma característica singular de divisão (DUARTE, CERQUEIRA, 2007).

No que tange a produção do $C R G$ voltada principalmente para a comunicação científica, podemos destacar os "bulletins", relatórios produzidos para a criação de vários esquemas de classificação para organizações como a Occupational Safety and Health (Genebra, Suíça); Research and Control Division of Allen and Hanbury Limited (indústria farmacêutica, Inglaterra); e a Bibliography of industrial diamond applications (Austrália) (SPITERI, 1995).

Em 1957, o CRG realizou a International Study Conference on Classification for Information Retrieval, em parceria com a International Federation of Documentation (FID), a Association of Special Libraries and Information Bureaux (ASLIB, hoje International Society for Information Management) e a University of London School of Librarianship and Archives. A conferência tratou de questões como publicação científica, indexação mecânica, guias de informação, tradução e revisão. 
Por mais onze anos de atuação, o grupo realizou e publicou trabalhos sobre a análise facetada, que continuou sendo estudada em trabalhos individuais de seus membros após o encerramento das atividades do $C R G$ em 1968.

O resultado das discussões do $C R G$ pôde ser visto nas contribuições dos membros para a Conferência Internacional sobre Informação Científica, realizada em Washington em 1958, dez anos após a Conferência da Royal Society que deu início a esse grupo de pesquisa. Foram apresentados trabalhos por Vickery, Foskett, Fairthorne, Farradane, e Palmer, tendo Foskett se dedicado especificamente a natureza das classificações facetadas em um documento sobre a metodologia da sua construção e Vickery foi o autor mais prolífico (BROUGHTON, 2011).

\section{CONSIDERAÇÕES FINAIS}

Em Organização do Conhecimento, no âmbito da Classificação, a análise facetada foi uma das principais heranças teóricas deixadas pelo Classification Research Group. A vertente atualmente influencia estudos semânticos na Internet e a organização e recuperação da informação digital. Como explica Broughton (2011), "para tornar a classificação facetada a base de toda a recuperação da informação, nota-se que no século XXI há uma nova apreciação do valor de análise facetada para a construção de todo um espectro de ferramentas de busca de informação".

Outro legado deixado pelo grupo para a Ciência da Informação foi a fundação do primeiro curso de pós-graduação em Ciência da Informação, depois transformado no Department for Infomation Science, na The City University, anteriormente o Northampton College of High Technology, localizado em Londres, Inglaterra (BARRETO, 2007).

Sobre os periódicos, um significativo patrimônio acadêmico deixado pela atuação do $C R G$ foi a publicação internacional Journal of Information Science, lançada em 1979 pelo Institute of Information Scientists (IIS) e que atualmente dissemina assuntos especializados no campo da Ciência da Informação. Cobre 
questões teóricas, políticas, aplicação e prática,avanços da tecnologia da informação, e técnicas de processamento da informação e inovação, tendo por base a sua compreensão teórica. A repercussão, visibilidade e qualidade de seus artigos são comprovadas pelos índices e status atuais alcançados.

A grande contribuição da Grã-Bretanha para a Ciência da Informação é o reconhecimento de que o $C R G$ estabeleceu desde o seu início, uma metodologia geral de análise de facetas para a recuperação de informação, tendo as seguintes características fundamentais de abordagem: a noção de categorização de conceitos como base para organização intelectual do conhecimento; exposição de forma clara e não ambígua das relações entre conceitos, tanto hierárquica dentro de facetas, quanto sintática por meio da interação de facetas; um sistema formal de sintaxe, com a síntese de conceitos para representar componentes e assuntos complexos; como consequência, a geração de uma lógica, previsível e teoricamente compreensível virtualmente da estrutura do conhecimento.

Um importante caminho herdado dessas pesquisas encontra-se na abordagem multifacetada, utilizada na organização de coleções digitais no ambiente acadêmico e na comunicação científica. A aplicação digital de técnicas facetadas complexas é essencial na modelagem de novos tipos de ferramentas, tais como taxonomias, ontologias, e aplicações na web semântica.

Na tentativa de avaliar o impacto do $C R G$ em termos práticos e o grau em que o objetivo de seu manifesto original para tornar a classificação facetada a base de toda a recuperação da informação, nota-se que no século XXI há uma nova apreciação do valor de análise facetada para a construção de todo um espectro de ferramentas de busca de informação.

A genialidade do $C R G$ reside na sua formação de análise facetada como uma metodologia generalizada para recuperação de informações, usando critérios específicos. Estes elementos essenciais da organização do conhecimento corroboram e melhoram as aplicações mais amplas de recuperação de informações em sistemas automatizados, especialmente hoje com o papel que a Internet tem ocupado, aproximando a perspectiva utópica da época à realidade do que se desejava com um Mundaneum e um "World Brain". 
O CRG permanece com uma forte e duradoura influência na Ciência da Informação, especialmente no campo da pesquisa em classificação prosseguido pelas organizações profissionais a Association for Information Management (Aslib), The International Federation for Information and Documentation (FID), a International Society for Knowledge Organization (ISKO), e da The Information Association for the Information Age (ASIST).

A influência da análise facetada sobre os regimes gerais de classificação é evidente. $\mathrm{O}$ impacto das descobertas do grupo de origem bretã sobre campos de estudo da Ciência da Informação e sobre a organização e recuperação da informação, especialmente após a internet, é inegável.

\section{REFERÊNCIAS}

ALVARES, L.; ARAÚJO JÚNIOR, R. H. Marcos históricos da ciência da informação: breve cronologia dos pioneiros, das obras clássicas e dos eventos fundamentais. TransInformação, Campinas, v. 22, n. 3, p. 195-205, set./dez., 2010. Disponível em: http://www.scielo.br/pdf/tinf/v22n3/a01v22n3.pdf. Acesso em: 03 dez. 2019.

BARRETO, A. Uma história da Ciência da Informação. In: TOUTAIN, Lidia Maria Brandão (Org.). Para entender a Ciência da Informação. Salvador: EDUFA, 2007. p. 13-34.

BERNAL, J. D. The social function of Science. London: George Routledge and Sons, 1939.

BLACK, A.; MUDDIMAN, D.; PLANT, H. The early information society: information management in Britain before the computer. Burlington: Ashgate, 2007.

BROUGHTON, V. Brian Vickery and the Classification Research Group: the legacy of faceted classification. In: GILCHRIST, A. .Proceedings of the Second National ISKO, UK Conference, 2011. Disponível em: https://pdfs.semanticscholar.org/16a5/0cd13ed90952ce5230fac4c60b5bc3939f 20.pdf. Acesso em: 03 dez. 2019.

BROUGHTON, V. Jack Mills, 1918-2010: an academic appreciation. Bliss Classification Association. 24 nov. 2010. Disponível em: http://www.blissclassification.org.uk/jackmills.shtml. Acesso em: 03 dez. 2019. 
BROUGHTON, V. The need for a faceted classification as the basis of all methods of information retrieval. Aslib Proceedings: New Information

Perspectives, v. 58. n. 1/2, p. 49-72, 2006.

BURKE, C. History of information science. Annual Review of Information Science and Technology, v. 41, n. 1, 2007.

CLUTE, J.; STABLEFORD, B. The Encyclopedia of Science Fiction: "Wells, H. G." 2016. Disponível em: http://www.sf-encyclopedia.com/entry/wells_h_g. Acesso em: 03 dez. 2019.

CRONIN, B. Brian Vickery: an appreciation. Journal of the American Society for Information Science and Technology, v. 61, n. 4, p. 850-851, April 2010.

DUARTE, E. A.; CERQUEIRA, R. F. Análise facetada: um olhar face a modelagem conceitual. Revista Digital de Biblioteconomia e Ciência da Informação, v. 4, p. 39-52, 2007. Disponível em:

https://periodicos.sbu.unicamp.br/ojs/index.php/rdbci/article/view/2020. Acesso em: 03 dez. 2019.

FAIRTHORNE, R. Morphology of Information Flow. Journal of the ACM, v. 14, n. 4, 1967.

FAIRTHORNE, R. The Mathematics of Classification, Proc. British Society of International Bibliography, London, v. 9, n. 4, 1947.

FAIRTHORNE, R. Towards information retrieval. Prague: Butterworths, 1961.

FARRADANE, J. A scientific theory of Classification and Indexing and its practical applications. Journal of Documentation, v. 6, Issue 2, 1950.

FARRADANE, J. The nature of information. Journal of Information Science, Issue 1, 1979.

FOSKETT, D. J. Classification and Indexing in Social Science. London:

Hardcover Butterworth \& Co Publishers, 1963.

FOSKETT, D. J. Classification for a General Index Language, Library Association Research Publication, n. 2, 1970.

FREIRE, G. H. Ciência da informação: temática, histórias e fundamentos.

Perspectivas da Ciência da Informação, Belo Horizonte, v. 11 n. 1, p. 6-19, jan./abr. 2006.

GARVEY, W. Communication: the essence of Science. London: Pergamon, 1979. 
GILCHRIST, A. Information Science in Transition. London: Facet Publishing, 2009.

HODGKIN, D. M. C. John Desmond Bernal: 10 May 1901- 15 September 1971. Biographical Memoirs of Fellows of the Royal Society, The Royal Society Publishing, v. 26, n. 16, 1980. Disponível em: http://rsbm.royalsocietypublishing.org/content/26/16. Acesso em: 03 dez. 2019.

HUXLEY, L. Life and letters of Thomas Henry Huxley. Cambridge University Press, 1901. Disponível em:

https://archive.org/details/lifeandletterst13huxlgoog. Acesso em: 03 dez. 2019.

JAPIASSÚ, H.; MARCONDES, D. Dicionário básico de Filosofia. Rio de Janeiro: Zahar, 2001.

JUSTICE, A. Information science as a facet of the history of British science: the origins of the Classification Research Group. American Society for

Information Science and Technology, 2004.

MEADOWS, A. J. Communication in science. London: Butterworths, 1974.

MILLS, J. A modern outline of Library Classification. Bombay: Asia

Publishing House, 1960.

MORE, T. A utopia. São Paulo: Martin Claret, 2015.

MUDDIMAN, D. Public science in Britain and the origins of documentation and information science, 1890-1950. In: RAYWARD, Boyd (Ed.). European

Modernism and the information society: informing the present, understanding the past. Hampshire: Ashgate, 2008.

PINHEIRO, L. V. R. Cenário da pós-graduação em Ciência da Informação no Brasil: influências e tendências. In: Encontro Nacional de Pesquisa em Ciência da Informaçãos, 8, 2007, Salvador. Anais [...]. Salvador: UFBA, 2007. 14 p.. Disponível em: http://www.enancib.ppgci.ufba.br/artigos/GT1--226.pdf. Acesso em: 03 dez. 2019.

PINHEIRO, L. V. R. Gênese da Ciência da Informação ou sinais anunciadores da nova área. In: AQUINO, M. A. (Org.). O campo da Ciência da Informação: gênese, conexões e especificidades. João Pessoa, UFPB, 2002.

PINHEIRO, L. V. R. Pesquisadores da Grã-Bretanha pioneiros na história da ciência da informação. In: ENANCIB, 14, 2013, Florianópolis. Anais [...] Florianópolis: ANCIB, 2013. Disponível em:

http://enancib.sites.ufsc.br/index.php/enancib2013/XIVenancib/paper/viewFile/5 24/243. Acesso em: 03 dez. 2019. 
RAYWARD, W. B. Douglas J. Foskett. Portsmouth: Chemical Heritage Foundation, 2000. Disponível em:

https://digital.sciencehistory.org/works/c247dt00x. Acesso em: 03 dez. 2019.

RAYWARD, W. B. European modernism and the information society: informing the present, understanding the past. Hampshire: Ashgate, 2008.

SPITERI, L. F. The Classification Research Group and the theory of integrative levels. The Katharine Sharp Review, n. 1, Summer 1995. Disponível em: http://web.archive.org/web/20011222083409/alexia.lis.uiuc.edu/review/summer 1995/spiteri.html. Acesso em: 03 dez. 2019.

VICKERY, B. Classificação e indexação nas ciências. Rio de Janeiro: BNG/Brasilart, 1980.

VICKERY, B. Concepts of Documentation. Journal of Documentation, v. 34 Issue 4, 1978.

VICKERY, B. Faceted classification for the web. Axiomathes, v. 18, n. 2, 2008.

VICKERY, B. A long search for information. Graduate School of Library and Information Science. University of Illinois at Urbana-Champaign, 2004.

Disponível em:

https://www.ideals.illinois.edu/bitstream/handle/2142/3808/g?sequence=1\&origi n=publication_detail. Acesso em: 03 dez. 2019.

WALKER, P. B. Robert Arthur Fairthorne: an appreciation. Journal of Documentation, v. 30, n. 2, p. 127-138, 1974.

WELLS, H. G. Experiment in autobiography: discoveries and conclusions of a very ordinary brain (since 1866). New York: Lippincott, 1967.

ZIMAN, J. Conhecimento público: a dimensão social da ciência. São Paulo: Edusp, 1979.

\title{
APPROACHES AND HISTORICAL CONTRIBUTIONS OF GREAT BRITAIN TO INFORMATION SCIENCE: A LOOK FROM THE CLASSIFICATION RESEARCH GROUP
}

\begin{abstract}
Introduction: The utopian perspectives reflected in Literature during the late nineteenth and early twentieth century are fertile environment for the emergence of the relevance of Britain's history to the area of Classification. It traces a historical overview of Information Science in Britain, describing the relevance and pioneering nature of the Classification Research Group and its members. Objectives: It aims to address scientific awakening under the influence of literary utopias, which culminated in the development
\end{abstract}


of classification methods for Knowledge Organization, through Britain's approaches and contributions under the light of the trajectory of the Classification Research Group. Methodology: The methodology of the descriptive research includes documentary survey and literature review on the subject, under the influence of the backbone of the commemorative work edited by Gilchrist (2009).Results: It was identified the historical influence of the period of utopias in the perspective of work in the Information Science of the researchers of the Classification Research Group. Conclusion: Concludes with the recognition of Britain's role and the pioneering spirit of the Classification Research Group, essentially the pioneering work of facet analysis for information retrieval, established as key to building a full spectrum of information search tools until today, and the foundation of the first postgraduate course in Information Science.

Descriptors: Information Science. Knowledge Organization. Classification History. Classification Research Group. Utopia.

\title{
ENFOQUES Y CONTRIBUCIONES HISTÓRICAS DE GRAN BRETAÑA A LA CIENCIA DE LA INFORMACIÓN: UNA MIRADA DESDE EL CLASSIFICATION RESEARCH GROUP
}

\begin{abstract}
RESUMEN
Introducción: Las perspectivas utópicas reflejadas en la Literatura durante el fin del siglo XIX y principios del siglo XX son un ambiente fértil para el surgimiento de la relevancia historia de Gran Bretaña para el área de la Clasificación. Traza un panorama histórico de la Ciencia de la Información en Gran Bretaña, describiendo la relevancia y el pionerismo del Classification Research Group y sus miembros. Objetivos: Tiene como objetivo es abordar el despertar científico bajo la influencia de las utopías literarias, que culminaron en el desarrollo de métodos de clasificación para la organización del conocimiento, a través de los enfoques y contribuciones de Gran Bretaña a la luz de la trayectoria del Classification Research Group. Metodología: La metodología de investigación descriptiva incluye encuesta documental y revisión de la literatura sobre el tema, bajo la influencia de la columna vertebral del trabajo conmemorativo editado por Gilchrist (2009). Resultados: Se identificó la influencia histórica del período de las utopías en la perspectiva de trabajo en la Ciencia de la Información de los investigadores del Classification Research Group. Conclusión: Concluye con el reconocimiento del papel de Gran Bretaña y del pionerismo del Classification Research Group, esencialmente por el trabajo precursor del análisis de facetas para la recuperación de información, establecido como fundamental para la construcción de todo un espectro de herramientas de búsqueda de información hasta hoy, y por la fundación del primer curso de posgrado en Ciencia de la Información.
\end{abstract}

Descriptores: Ciencia de la información. Organización del Conocimiento. Historia de la Classificación. Classification Research Group. Utopia. 